\title{
The effectiveness ofproanthocyanidins cacao pods (theobroma cacao I) on increasing socket epithelial thickness post toothextraction in wistar rats
}

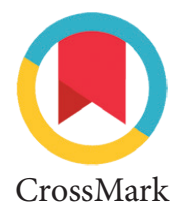

\author{
Yani C. Rahayu, ${ }^{1 *}$ Budi Yuwono, ${ }^{2^{*}}$ Alifia Wandansari ${ }^{1}$
}

\section{Abstract}

Objective: The aim of this study was examine theeffectivenessof proanthocyanidins cacaopods (Theobroma cacao L) extract on increasing socket epithelial thickness post tooth extractionin Wistar Rats. Proanthocyanidins has benefis as antiinflammation, antioxidant and antibacteria agent. Post-extraction wound can cause complication, which can make long the healing process. This is where anti-inflammatory is needed to prevent infection, so that it can avoid bacterial contamination and can shorten the inflammatory process. Material and Methods:These study was an experimental laboratory research on thickness of socket epithelium of Wistar rats given proanthocyanidins cacao pod extract post extraction. A total of 24 male Wistar rats was divided into 3 group; which was treated with $100 \mathrm{mg} / \mathrm{ml}$ proanthocyanidins cocoa pod extract as treatment group, distilled placebo gel as negative control group and alvogyl as positive control group. 0n day 7 and day 14 the sampel was sacrified and tissue processing was made. The gingival epithelial thickness was determined by software image raster on light microscopy.

Results:Analysisof One way Anova showed there was a significant difference 0.001 between groups. The epithelium of treatment group, was thicker than the control group significantly.

Conclusion:Proanthocyanidins cocoa pods (Theobroma cacao L) extract effectiveincreasing the thickness of socket epithelium postextraction in Wistarrats.
'Department of Oral Biology, Faculty of Dentistry, University of Jember, Jember, Indonesia ${ }^{2}$ Department of Oral and Maxillofacial Surgery, Faculty of Dentistry, University of Jember, Jember, Indonesia
*Correspondence to: Yani C. Rahayu, Department of Oral Biology, Faculty of Dentistry, University of Jember, Jember, Indonesia yani.fkg@unej.ac.id; budiby99@yahoo.com

Received: 13 August 2019 Revised: 23 March 2020 Accepted: 29 March 2020 Available online: 1 April 2020

Keywords: Epithelialgingivalthickness, Proanthocyanidins, Cocoa pod, Tooth extraction

Cite this Article: Rahayu YC, Yuwono B, Wandansari A. 2020. The effectiveness ofproanthocyanidins cacao pods (theobroma cacao I) on increasing socket epithelial thickness post toothextraction in wistar rats. Journal of Dentomaxillofacial Science 5(1): 12-16. D0I: 10.15562/ jdmfs.v5i1.963

\section{Introduction}

Commercial cocoa is obtained from beans that originated as seeds from the ripe pods of the plant, Theobroma cacao, which is cultivated in plantations in tropical regions throughout the world. Indonesia is the third largest of cocoa producing countries. ${ }^{1}$ A growing body of scientific evidence is becoming available to support that cocoa components with antioxidants and anti-inflammatory activities. Cocoa pods contain of a mixture of condensed flavonoids or tannins (proanthocyanidins) or polymerized. ${ }^{2}$ The condensed tannin or proanthocyanidins is the most polyphenol component in cocoa which is $58 \% .^{3}$ Based on previous research, proanthocyanidins extracted from black raspberry seeds has anti-inflammatory activity through its ability to inhibit lipopolysaccharide in inducing proinflammatory mediators in the inflammatory process. ${ }^{4}$ Aside from being anti-inflammatory, proantocyanidins also has an antioxidant and antibacterial effect. The activity of proanthocyanidins as an antibacterial is through inhibition of bacterial cell walls in the form of disturbances in cell wall function and cell aggregation. While antioxidant activity is by preventing oxidative stress. ${ }^{5}$
In the field of dentistry many treatments can cause gingival injury. Tooth extraction is the most common procedure in oral and maxillofacialsurgery. ${ }^{6}$ Post-extraction wounds can heal easily but can also cause complications caused by various things, which inhibit the healing process. ${ }^{7}$ Therefore a faster healing process is expected to minimize the post-extraction complications.

The healing process generally includes hemostasis, inflammation, proliferation (angiogenesis, epithelialization and fibroplasia) and maturation. ${ }^{8}$ The wound healing process can be seen from several parameters, one of which is epithelialization. Epithelialization occurs when epithelial cells begin to proliferate at the edges of the wound layer by layer and continue until epithelial cells have returned to their normal phenotype and have reconnected with the basement membrane. Keratinocytes are responsible for restoring the epidermis after injury through a process known as epithelialization. ${ }^{9}$ But if the inflammatory process that occurs after tooth extraction is excessive, it can inhibit the healing process. This is where anti- inflammatory is needed to prevent infection, so it can 
avoid bacterial contamination and can shorten the inflammatory process to go to the next phase. The anti-inflammatory drugs used after tooth extraction are very numerous, one of them is alvogyl. Alvogyl consists of eugenol (analgesic, anti-inflammatory, iodoform (antiseptic), butamen (anesthesia). Unfortunately, anti-inflammatory drugs have a variety of side effects, such as gastrointestinal bleeding, damaging kidney function. Therefore, an alternative drug should be developed that can accelerate the process of wound healing side as minimal as possibleCocoa peel extract at concentrations of 5\%, 10\%, and $15 \%$ has an anti-inflammatory effect on the number of macrophage cells. ${ }^{10}$ Active macrophages produce cytokines that affect proliferation, migration of fibroblasts, endothelial cells, and epithelium.

Based on the previous research, many uses of anti-inflammatory drugs in gel dosage forms derived from natural ingredients. The gel preparations in this study used Na-CMC as a gel base. The $\mathrm{Na}-\mathrm{CMC}$ base has advantages when it was given an extract, the results do not affect the spread. As well as in the application of wound tissue, ${ }^{11}$ for example, such as in a tooth extraction, post extraction is easier to place. Based on this condition, the researchers' curiosity arose to determine the effect of cocoa peel proanthocyanidins extract gel (Theobroma cacao L) on increasing epithelial thickness of wistar rat tooth socket after extraction.

\section{Material and Methods}

The materials used were digitalscale (ohaus), erlenmeyer, glass stirrer, small funnel, rotary evaporator,freeze dryed, vial, desicator, spectrophotometer, masker (diapro), evergloves, excavator, syringe, object glass dan deck glass, microtome (Leica RM 2135), base mole (daikin), waterbath (memmert), micropipet, automatic processing tissue, pinset, slide warmer.The type of research used is laboratory experimental research with the post test only control group design. This research was conducted at the Phytochemical Laboratory of the Faculty of Pharmacy and Biomedical Laboratory of the Faculty of Dentistry, University of Jember.. The sample consisted of 24 male wistar rats which were then adapted to the enclosure environment for 7 days and given standard rat food and drank every day adlibitum.

\section{Procedure of Proanthocyanidins Extract}

The cocoa pods used in the study were obtained from cocoa farmers in Jember, East Java. The stage of making extracts is cocoa fruit as much as $5 \mathrm{~kg}$ is cleaned, cut, then dried in the sun after it is carried out shredding to form fine shavings. Then the results of the shavings are blended to get a fine powder and weighed. Next as much as 100 grams of powdered cacao fruit which has become powder is added with $70 \%$ acetone $700 \mathrm{ml}$ and $300 \mathrm{ml}$ of distilled water were put into erlenmeyer. Then the extract solution is stirred using stirring the glass in a counterclockwise direction. After that the solution is put into a waterbath shaker at $50^{\circ} \mathrm{C}$ for 20 minutes. After that the extract solution was centrifuged at a speed of $2000 \mathrm{rpm}$ for 10 minutes to separate the extract liquid and the supernatant. After the extract solution is separated from the supernatant then the extract solution is inserted into the rotary evaporator. The extract solution is then placed into a petri dish, then put in the oven. After there is a thick portion at the base of the petri dish, then the petri dish is removed from the oven. Then the thick part at the bottom of the petri dish is taken and placed in a smallglass. ${ }^{12}$

\section{Analysis of Proanthocyanidins with HPLC Method}

Proanthocyandins extract chromatographic analysis was carried out by using HPLC method (pump 2695, diode array 2996 detector, Waters) combined with an ostadecylsilane (ODS) C18 analytic column $(4.6 \times 250 \mathrm{~mm})$. The column was operated at $25^{\circ}$ C. The Compounds were detected between 200 and $400 \mathrm{~nm}$. The mobile phase of HPLC consisted of $2 \%(\mathrm{v} / \mathrm{v})$ acetic acid in water (eluent $\mathrm{A})$ and $0.5 \%$ acetic acid in water and acetonitrile (50:50, v/v; eluent $\mathrm{B})$. The gradien program was as follows: $0-10$ minutes, $5-13 \%$ of $\mathrm{B} ; 10-15$ minutes, $13-16 \%$ B; $15-40$ minutes, $16-40 \%$ B; $40-43$ minutes, $40-43 \%$ of B; $43-48$ minutes, $43-50 \%$ B; 4858 min, $50-100 \%$ of B; $58-63 \mathrm{~min}, 100-5 \%$ of B. ${ }^{13}$

Mass spectrometry analysis of cocoa pod proanthocyanidin extract were performed by an Agilent 6460 triple quadrupolemass spectrometer equipped with ESI sources (Agilent Technologies) in negative ionization mode. The nebulizer pressure was set to $45 \mathrm{psi}$ and the flow rate of drying gas was $5 \mathrm{l} / \mathrm{min}$. The flow rate and the temperature of the sheath gas were $11 \mathrm{l} / \mathrm{min}$ and $350^{\circ} \mathrm{C}$. The mass ranged from $\mathrm{m} / \mathrm{z} 50$ to 2000. Chromatographic separations were done on the ODS C18 analytic column (4.6 $\times 250 \mathrm{~mm}$ ) using anAgilent 1290 Infinity HPLC system (Agilent Technologies). The eluent was split and approximately $0.3 \mathrm{ml} / \mathrm{min}$ was introduced into the mass detector. Selective ion monitoring was used to select molecular ions of the isomers from the procyanidins group in extracts of cocoa pod proanthocyanidin for their quantification. An Agilent Mass Hunter Workstation was used for data acquisition and processing.the results were obtained in the form of proanthocyanidins extract with its constituents which was proanthocyanidins $\mathrm{A} 2$ and $\mathrm{B} 2{ }^{12,13}$ 


\section{Procedure of Proanthocyanidins Extract Gel}

$96 \mathrm{ml}$ of aquadest was measured by measuring flask and poured into mortar. Then 4 grams of CMC-Na was measured by analytic scales and put into a mortar containing aquadest. It was let stand for about 10-15 minutes and then stirred until it formed a yellow gel. The weight of CMC-Na mixture and aquadest which had become 45-gram gel and $100 \%$ proantocyanidin from the rind of (theobroma cacao L). 5 grams were added into the mortar and mixed until homogeneous to obtain the gel extract of proanthosiandin cocoa pod (Theobroma cacao L.) with a concentration of $10 \%{ }^{14}$

\section{Animal Experiment Treatment}

This experimental laboratory study was approved by ethical committee of medical research Faculty of Dentistry Universitas Jember (No. 117/UN.25.8/ KEPK/DL/2018). Experimental animals were divided into 3 groups: negative control group, positive control and treatment group. And each group was divided into 2 subgroups based on observation days, namely the 7th and 14th days, the number of each was 4 rats per subgroup. The whole group was extracted from the lower left first molar. Previously, experimental animals were anesthetized using general ketamine anesthesia with a dose of $20-40 \mathrm{mg} / \mathrm{kg}$ body weight in the rat thighs. Extraction is done using an excavator. In the negative control group given a placebo gel, positive control was given alvogyl and the treatment group was given the cocoa fruit skin proanthocyanidins extract gel once aday.The animal sacrifice was carried out on the 7th and 14th day by inhalation using ether doses. Then proceed with taking the left lower jaw of the mouse in the posterior region.

Table 1 The AverageEpithelial thickness $(\mu \mathrm{m})$ of dental sockets in day7andday 14

\begin{tabular}{lcc}
\hline Groups & Day-7 & Day-14 \\
\hline C & $17.08 \pm 3.65$ & $16.89 \pm 0.79$ \\
A & $24.56 \pm 4.93$ & $23.81 \pm 1.65$ \\
P & $25.69 \pm 1.82$ & $23.84 \pm 3.07$ \\
\hline
\end{tabular}

Values were expressed as mean \pm standard deviation $(\mathrm{x} \pm \mathrm{SD})$

$\mathrm{C}$ : control group (placebo gel)

A : (Alvolgyl gel)

$\mathrm{P}$ : Proanthocyanidins gel

Table 2 Results of the One-way Anova test

\begin{tabular}{|c|c|c|c|c|c|}
\hline & Sum of Squares & Df & Mean Square & $\mathbf{F}$ & Sig. \\
\hline \multicolumn{6}{|c|}{ Epithelial thickness $(\mu \mathrm{m})$} \\
\hline Between Groups & 308.701 & 5 & 61.740 & 6.898 & .001 \\
\hline Within Groups & 161.114 & 18 & 8.951 & & \\
\hline
\end{tabular}

\section{Measurement of Epithelial Thickness}

The tissue was fixed using a 10\% formalin buffer solution for at least 24 hours followed by decalcification using $10 \%$ formic acid for 7 days. Next is the network preparation process. This was followed by tissue processing (dehydration process), and embedding into paraffin wax block. The blocks were cut into $5 \mu \mathrm{M}$ using microtome. The tissue slides were stained using hematoxylin and eosin staining. Epithelial thickness is determined from the stratum corneumtothebasal stratum at the gingival epithelium covering the tooth socket. Observations were made using a binocular microscope (olympus photo slide BX51 with DP71 cam $12 \mathrm{mpx}$ and camera optilab) with $100 x$ magnifications with the help of optilab and raster image software. Epithelial thickness was obtained from measurements in 3 fields of view, each field of view measured in areas that had thin, medium and thick epithelial thickness and were measured by threeobservers.

\section{Statistical analysis}

The data obtained from the study conducted was tested using SPSS software. The data were analyzed withANOVA (one-way analysis of variance) followed by the post hoc Least Significant Difference test to determine differences among the groups. The results were expressed as mean \pm standard deviation. The significance of the differences between mean values of each data measured was determined based on $\mathrm{p}$ value, where $\mathrm{P}$ value $<0.05$ is considered statistically significant.

\section{Results}

Based on the research that has been done, it was found that the average gingival epithelial thickness of male wistar rats after tooth extraction between the negative control group, positive control and treatment grou on day7 and dan 14 . Table 1 shows that the average epithelial thickness of dental sockets in day-7 $(25.69 \mu \mathrm{m})$ treatment group (P) compared to Alvolgyl, the positive control group (A) $(24.56 \mu \mathrm{m})$ and negative control (C) $(17,08 \mu \mathrm{m})$, while the greatest epithelial thickness at day 14 wasowned by the treatment group $(\mathrm{P})$ and the one with thelowest epithelial thickness was the negative control group (C).

One-way ANOVA test results obtained a significance value of $0.001(\mathrm{p}<0.05)$, which means that there is a significant difference in mean epithelial thickness between all groups. Furthermore, to find out which groups had significant differences table 2. The results of the study can be seen in figure 1A - figure1F. 

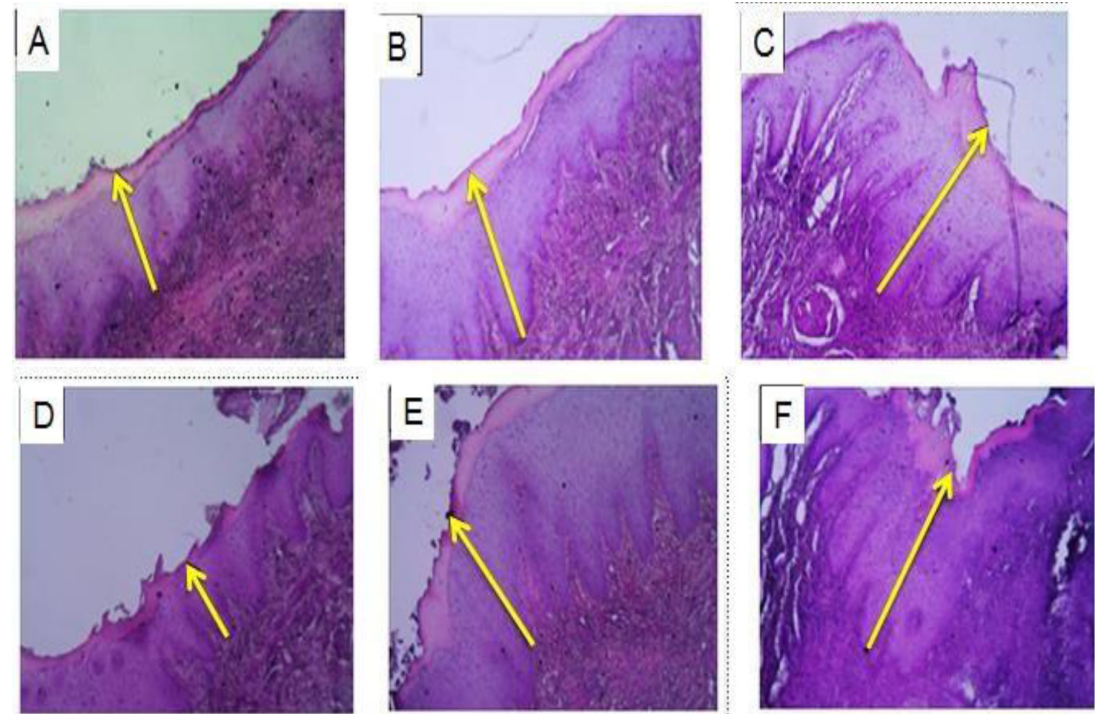

Figure 1 Histological picture of 7th dayepithelial thickness after extraction (yellowarrow) with HE staining at 100x magnification: A. Negative control group, B. Positive control group (alvolgyl), C. Treatment group (proanthocyanidins). Histological description of epithelial thickness of the 14th day post extraction (yellowarrow) by HE staining at 100x magnification: D. Negative control group, E. Positive control group, F. Treatment group(proanthocyanidins)

\section{Discussion}

Cacao pod husk has potential as an anti-inflammatory, anti-bacterial and antioxidant natural medicine. ${ }^{15}$ The role as anti-inflammatory is to reduce the expression of MCP-1 which is a proinflammatory cytokine. The expression of MCP-1 decreased when the concentration of grape seed and cacao extract was more than $50 \mathrm{mg} / \mathrm{ml}$ and $60 \mathrm{mg} / \mathrm{ml}$. When the inflammatory process is shorter, the proliferative ability of TGF- $\beta$ (transforming growth factor- $\beta$ ) will not be inhibited, so the epithelialization process can increase. Because TGF- $\beta$ and KGF (keratinocyte growth factors) are growth factors that affect keratinocytes in the epithelialization process. KGF has a role in increasing epithelial repair by modulating expression, deposition and organization of fibronectin in epithelial cells. Whereas TGF- $\beta$ is a factor that plays a role in stimulating the differentiation of epithelial cells. ${ }^{16}$ In general, the epithelialization process can be proven by measuring the thickness and width of the epithelial gap formed. ${ }^{17}$

The epithelialization process will last until the epithelium covers the entire wound surface and undergoes maturation and then its thickness will experience a constant phase due to the epithelial cell turnover process. Apart from acting as an anti-inflammatory agent, pronatehcyanidins also has an antioxidant and antibacterial role. The mechanism of tannins antibacterial is through reaction with the cell membrane, inactivation of the enzyme, and inactivation of the function of the genetic material. The mechanism of tannins as antibacterial agent are inhibiting the enzyme reverse transcriptase and DNA topoisomerase so bacterial cells cannot be formed..$^{18}$ The antimicrobial activity possessed by pronatehcyanidins can inhibit extracellular enzymes, so that microbial growth can also be inhibited. In addition, proanthocyanins also inhibits bacterial cell walls through interference with cell wall function and cell aggregation. Proanthocyanidins has a higher activity as an antioxidant than ordinary polyphenols. ${ }^{5}$

In vitro and in vivo studies also show that procyanidins oftannins can inhibit damage caused by oxidative stress through molecular scavenging. In addition, the antioxidant activity of proanthocyanidins is also related to the presence of catechol groups. Many processes can produce free radicals, such as ROS. If left unchecked it will cause oxidative damage to DNA, lipids, and proteins that produce degradative effects that contribute to causing disease. ${ }^{5,19}$

In this study the extract of proanthocyanidins cocoa pods (Theobroma cacao L) was made in gel preparations. The gel preparations were made using CMC-Na material, because if it was given an extract, the results did not affect the spreadability. And in the application of wound tissue, for example, as in the tooth socket after extraction it is easier toplace.The analysis statistic test results showed a significant difference between groups in the treatment groupfor the negative control group both on day 7 and day 14 which means that the administration of proanthocyanidins extract of cocoa pods (theobroma cacao L) can improve the epithelialization process indicated by an increase in epithelial thickness.

\section{Conclusion}

Based on the results of the research that has been carried out, it can be concluded that the extract of proanthocyanidins $100 \mathrm{mg} / \mathrm{ml}$ of cacao pods (Theobroma cacao L.) can increase the epithelial thickness of wistar rat tooth socket after extraction. Thus, the proanthocyanidins extractgel $100 \mathrm{mg} / \mathrm{ml}$ can be developed as an herbal medicine after tooth extraction.

\section{Acknowledgment}

The reseachers like to thank to the Institution of Research and Public Service (LP2M) University of Jember for the opportunity dan funding provided for us to publication this paper. 


\section{Conflict of Interest}

The authors declare that there is no conflict of interests regarding the publication of this paper.

\section{References}

1. Ardhana MM, Fleet HG. The microbial ecology of cocoa bean fermentations in Indonesia. Int J Food Microbiol 2003;86: 87-99.

2. Smeriglio A, Barreca D, Bellocco E, et al. Proanthocyanidins and hydrolysable tannins: occurrence, dietary intake and pharmacological effects. Br J Pharmacol 2017;174: 1244-1262.

3. Hii CL, Law CL, Suzannah S, et al. Polyphenols in cocoa (theobroma cacao L.). As J Food Ag-Ind 2009;2: 702-722.

4. Park $\mathrm{M}$, Cho $\mathrm{H}$, Jung $\mathrm{H}$, et al. Antioxidant and anti-inflammatory activities of tannin fraction of the extract from black raspberry seeds compared to grape seeds. J Food Biochem 2014;38: 259-270.

5. Huang Q, Liu X, Zhao G et al. Potential and challenges of tannins as an alternative to in-feed antibiotics for farm animal production.AnimNutr.2018;4:137-150.

6. Del-Fabbro M, Bucchi C, Lolato A, et al. Healing of postextraction sockets preserved with autologous platelet concentrates. a systematic review and meta-analysis. J Oral Maxillofac Surg 2017;75: 1601-1615.

7. Zakia F, Novita CF, Sunnati. Distribusi Frekuensi Faktor Penyebab Ekstraksi Gigi PasienDi Rumah Sakit Umum dr. Zainoel Abidin Banda Aceh Periode Mei-Juli 2016. J Caninus Dentist 2016;1: 32-38.

8. Leoni G,Neumann PA,Sumagin R, et al. Wound repair: role of immune-epithelial interactions. Mucosal Immunol 2015;8: 959-968.

9. Pastar I, Stojadinovic O, Yin NC. Epithelialization in wound healing: a comprehensive review. Adv Wound Care (New Rochelle). 2014;3: 445-464.

10. Baharudin M. The antiinflammatory test of cocoa pods (theobroma cacao 1.) extractonmale mice. Sumatra Utara: Universitas Sumatra Utara;1996.

11. Maulina, L, Sugihartini, N. Formulation of ethanol mangosteen pods gel extract (garcinia mangostana 1.) with variation of gelling agent for preparation of burns. Pharmaciana 2015;5: 43-52.
12. Wissam Z, Bashour G, Abdelwahed W, et al. Simple and fast method for the extraction of polyphenol and the separation of proanthocyanidins from carob pods. SAJP 2013;2: 375-380

13. Qiang LV, Luo1 F, Zhao X, et al. Identification of proanthocyanidins from litchi (litchi chinensissonn.) pulp by LC-ESIQ-TOF-MS and their antioxidant activity. Plos One 2015;10: 1-17.

14. Hafidhah N, Hakim RF, Fakhurranzi. The effect of cacao seed extract in different concentration on growth of Enterococcus faecalis. J Canalis Dentist 2017;2: 341-343. (In Indonesian, English abstract).

15. Yuwono B, Elga S, Christmarini DM. The potential of cacao (theobroma cacao 1.) pod husk extract on the number of fibroblast cells of wistar rats wound post-tooth extraction. Int J App Pharm 2019;11: 30-32.

16. Simon BI, Zatcoff AL, Kong JJW, et al. Clinical and histological comparison of extraction socket healing following the use of autologous platelet-rich fibrin matrix (PRFM) to ridge preservation procedures employing demineralized freeze dried bone allograft material and membrane. Open Dent J 2009;3: 92-99.

17. Nagar HK, Srivastava AK, Srivastava R, et al. Pharmacological investigation of the wound healing activity of cestrum nocturnum (L.) ointment in wistar albino rats. J Pharm (Cairo) 2016;2016: 9249040.

18. Setyorini D, Rahayu YC, Sistyaningrum T. The effects of rinsing red beet root (Beta vulgaris L.) juice on streptococcus sp. dental plaque. J Dentomaxillofac Sci 2017;2: 15-17.

19. Sutcliffe TC, Winter AN, Punessen NC, et al. Procyanidin B2 protects neurons from oxidative, nitrosative and excitotoxic stress. Antioxidants 2017;6: 77.

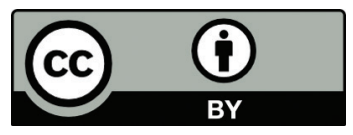

This work is licensed under a Creative Commons Attribution 